\title{
Development of optical fibers for food irradiation dosimeter
}

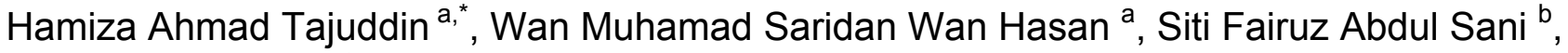 \\ Siti Aiasah Hashim ${ }^{c}$
}

a Department of Physics, Faculty of Science, Universiti Teknologi Malaysia, 81310 UTM Johor Bahru, Johor, Malaysia

b Department of Physics, Faculty of Science, University of Malaya, 50603 Kuala Lumpur, Malaysia

Malaysian Nuclear Agency, Bangi, 43000 Kajang, Selangor, Malaysia

* Corresponding author: hamizaahmadtajuddin@gmail.com

\section{Article history}

Submitted 25 January 2018

Revised 29 March 2018

Accepted 11 July 2018

Published Online 4 February 2019

\begin{abstract}
Different technologies and methods for enhancing food quality have been developed and applied in the last few decades. One of the latest technologies is by using ionizing radiation. Food irradiation is the technology that improves the safety and extends the shelf life of food by reducing or eliminating harmful microorganisms and insects. In order to provide for food safety, proper control or radiation detector of irradiated food seems very critical to facilitate international trade of irradiated foods and to enhance consumer confidence. In present studies, germanium-doped (Gedoped) optical fibers of various forms and dimensions were used as radiation detector. The fibers were irradiated using electron beam (EPS 3000), with doses from $1 \mathrm{kGy}$ up to $10 \mathrm{kGy}$, exceeding the dose range of all commercial high dose dosimeters used in food irradiation industry. A study has been made of linearity, reproducibility, and fading. The fibers showed a linear dose response over the studied range doses with mean of reproducibility less than $5 \%$ variation between 1 st exposure and 2 nd exposure. TL fading of Ge-doped flat fibers has been found to be $<8.7 \%$.
\end{abstract}

Keywords: Food irradiation, ionizing radiation, Ge-doped optical fibers, dosimetry, electron beam

\section{INTRODUCTION}

Food irradiation has been recently became one of the most successful methods to preserve food with minimum interruption to the functional, nutritional, and sensory properties of food products. According to Farkas et al. [1], food irradiation is conducted commercially, in order to improve the shelf life of the product. This food processing involves controlled application of energy from ionizing radiations such as gamma rays, X-rays, and electron beam for food preservation. Prior to 1980, limited work was carried out for the development of reliable detection methods for irradiated foods, including Perspex (PMMA) blocks, radiochromic film, high-purity Ge detectors (HPGe) and both ceric-cerous and ferrous sulphate (special solution). Unfortunately, some of these methods have poor sensitivity, limited dose range [2], contained toxic chemicals [3] and required a complex measurement process [4]. After 1980, extensive researches have been undertaken which resulted in the development of a range of test methods that could be used to reliably determine the irradiation status of a wide variety of foods.

Recently, some research groups started to use flat optical fibers as radiation dosimeter and some other researchers have been developed doped optical flat fibers with possible use as dosimeter material [5]. Flat fibers combine the structural advantages and functional benefits of planar devices [6]. Therefore, the main interest in this study was to investigate the dosimetric properties of fabricated Ge-doped optical flat fibers for usage in food irradiation industries. Table 1 shows the type of food and maximum dose (kGy) that required for food irradiation according to specific country. There were several applications of food irradiation in different dose levels (see Table 2).

\section{MATERIALS AND METHODS}

\section{Preparation of Ge-doped flat fibers}

An uncollapsed germanium silica dioxide (Ge-doped $\left.\mathrm{SiO}_{2}\right)$ preform was fabricated using the standard modified chemical deposition (MCVD) technique. This method was carried out for the present TL media at the MCVD Laboratory, Cyberjaya Campus, Multimedia University, Malaysia. Reference made to the gas flow rate where $6 \mathrm{~mol} \%$ of Ge flat fiber preform was produced. The flat fibers were produced by applying vacuum pressure and temperature to the doped hollow silica preform during the fiber drawing process [6]. This preform was drawn into a fiber cane of diameter 3-4 $\mathrm{mm}$, at the facilities of the flat fibers laboratory, Department of Electrical Engineering, University of Malaya. The commercial Ge-doped $9 \mu \mathrm{m}$ diameter optical fibers were observed to have Ge concentration in the range of 0.09 to 0.13 weight $\mathrm{mol} \%$ of $\mathrm{Ge}$.

\section{Preparation of the samples before irradiation process}

To prepare the flat fibers for irradiation, four steps were taken: (i) removal of the thin outer protective polymer layer of the fibers using fiber stripper (Model 8PK-326, Prokit's Industries Co Ltd, Taipei) (ii) cleaning of the bare fibers using propanol to remove any dust and oil; (iii) cutting of the fibers into $3.0 \pm 1.0 \mathrm{~mm}$ lengths using optical fiber cleaver (Model CT-07 Fujikura High Precision, Tokyo) and (iv) annealing process. All samples were annealed using a furnace oven (Model TLD lab 01/400, Delta Advantech, Selangor) at a temperature of $400{ }^{\circ} \mathrm{C}$ for 1 hour and then slowly cooled to room temperature for 8 hours. The objective of annealing process was to eliminate any remaining TL signal by emptying the high temperature traps or interstitials [10].

Each optical flat fiber was weighted using an analytical balance (Model BSA224S-CW, Sartorius, Gottingen) and placed in a gelatine 
capsule. Each capsule contained at least four pieces of flat fibers. Vacuum tweezers (Dymax 5, Charles Austen, Surrey) have been used to handle the fibers, in order to minimize the formation of scratches on surface and deposition of dust or finger oil. The fibers were kept in a black box to minimize exposure to light.

Table 1- Some examples of current uses of food irradiation in different countries $[7,8]$.

\begin{tabular}{|c|c|c|c|}
\hline Region & Country & Food & $\begin{array}{l}\text { Maximum } \\
\text { dose (kGy) }\end{array}$ \\
\hline \multirow{5}{*}{$\begin{array}{c}\text { The } \\
\text { Americas }\end{array}$} & USA & Pork & 1.0 \\
\hline & \multirow{3}{*}{ Canada } & Poutry & 3.0 \\
\hline & & Potato & 0.1 \\
\hline & & Spices & 10.0 \\
\hline & Brazil & Strawberries & 3.0 \\
\hline \multirow{6}{*}{ Europe } & France & $\begin{array}{l}\text { Camembert } \\
\text { Cheese }\end{array}$ & 3.5 \\
\hline & \multirow{3}{*}{ The Netherlands } & Egg white & 4.0 \\
\hline & & Frog-legs & 5.0 \\
\hline & & Dried fruits & 1.0 \\
\hline & \multirow[t]{2}{*}{ U.K } & $\begin{array}{l}\text { Roots and } \\
\text { tubers }\end{array}$ & 0.2 \\
\hline & & Shellfish & 3.0 \\
\hline \multirow{6}{*}{$\begin{array}{l}\text { Asia and } \\
\text { Europe }\end{array}$} & \multirow[t]{2}{*}{ China } & Garlic & 0.1 \\
\hline & & Rice & 1.0 \\
\hline & \multirow[t]{2}{*}{ Thailand } & Mango & 1.0 \\
\hline & & $\begin{array}{l}\text { Fermented } \\
\text { sausage }\end{array}$ & 4.0 \\
\hline & \multirow[t]{2}{*}{ South Africa } & Avocado & 3.0 \\
\hline & & Fruit juice & 3.0 \\
\hline
\end{tabular}

Table 2: Application by overall average dose [9].

\begin{tabular}{ccc}
\hline & Application & Dose (kGy) \\
\hline $\begin{array}{c}\text { Low dose } \\
\text { (up to 1 kGy) }\end{array}$ & $\begin{array}{c}\text { Inhibit sprouting } \\
\text { Delay fruit ripening } \\
\text { Stop insect/parasite } \\
\text { infestations }\end{array}$ & $0.03-0.15$ \\
& Delay spoilage of meat & $0.03-0.15$ \\
\hline Medium Dose & Reduce risk of pathogens in \\
(1 to 10 kGy) & $\begin{array}{c}\text { meat } \\
\text { Increase sanitation of spices }\end{array}$ & $1.50-3.00$ \\
\hline High dose & Sterilization of packaged & $3.00-7.00$ \\
(above 10 kGy) & $\begin{array}{c}\text { meat } \\
\text { Increase juice yield }\end{array}$ & $25.00-70.00$ \\
\hline & Improve re-hydration & $25.00-50.00$ \\
$25.00-50.00$ \\
\hline
\end{tabular}

\section{Electron beam irradiation}

There are several types of radiation used in food irradiation, e.g electron, gamma or X-ray irradiations. In this study, electron beam was chosen since it was the only radiation for food processing that currently is available at Malaysian Nuclear Agency, Bangi. The fiber samples were irradiated using electron beam machine EPS 3000. The samples were irradiated to various doses from $1 \mathrm{kGy}$ up to $100 \mathrm{kGy}$. Electron beam can be used to treat food and food ingredients in order to eliminate microbial pathogens or at higher dose to sterilize food ingredients. Each optical fiber was placed in capsule and categorized accordingly prior to irradiation. Figure 1 shows the samples placed on the conveyer belt during irradiation.

\section{TL measurement}

The TL was read out by a TLD reader (Model 3500, Harshaw Chemical Company, Cleveland) at Nuclear Laboratory, Universiti Teknologi Malaysia, after 24 hours of post-irradiation. During the reading process, nitrogen gas was flowed through the sample chamber in order to suppress light stimulation from air and also to reduce the oxidation of the heating element and the fibers [11]. The timetemperature profile used in this readout process was as follows: preheat temperature of $50{ }^{\circ} \mathrm{C}$, heating rate of $10^{\circ} \mathrm{C} \cdot \mathrm{s}^{-1}$ and maximum temperature for data acquisition of $400{ }^{\circ} \mathrm{C}$. This time-temperature profile has been set to obtain the complete capture of TL glow curve under optimum conditions.

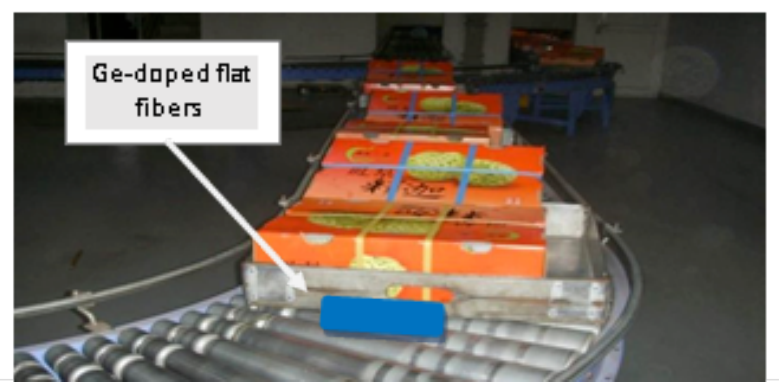

Figure 1 Fruits on the conveyor belt before electron irradiation.

\section{RESULTS AND DISCUSSION}

In order to explore the possibility of using these fibers in food irradiation, dosimetric properties such as dose response, reproducibility of the TL yield, and thermal fading were investigated for doses from $1 \mathrm{kGy}$ up to $100 \mathrm{kGy}$.

\section{TL response}

The dose response is one of specific interest in seeking a practicable measurement device. Different doses (1 kGy up to $100 \mathrm{kGy}$ ) were used for the purpose of TL response study. Based on the coefficient of determination $\left(\mathrm{R}^{2}\right)$ for each flat fiber, all the fibers showed linear response in the $1-100 \mathrm{kGy}$ range, as presented in Figure. 2. We defined the normalized dose response function (or supralinearity index) $f(\mathrm{D})[11]$ as:

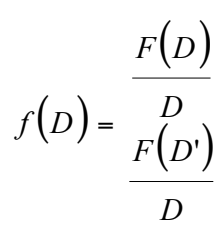

where $\mathrm{F}(\mathrm{D})$ is the dose response at a dose $D$ and $D^{\prime}$ is a low dose at which the dose response is linear. Therefore, our ideal dosimeter would satisfy $f(\mathrm{D})=1$ only over a wide dose range. Mostly, it was found that $f(\mathrm{D})=1$ only over a narrow dose range, up to a few Gy, in many TLD materials. In this study, the most ideal dosimeter was flat fibers doped Ge with $R^{2}=0.979$. Supralinearity, defined as $f(D)>1$, was commonly observed, while sublinearity (f (D) $<1$ was mostly observed during the approaching saturation. Some TL material has $\mathrm{f}$ (D) = constant over entire dose range and the response of the dosimeter was the same [12].

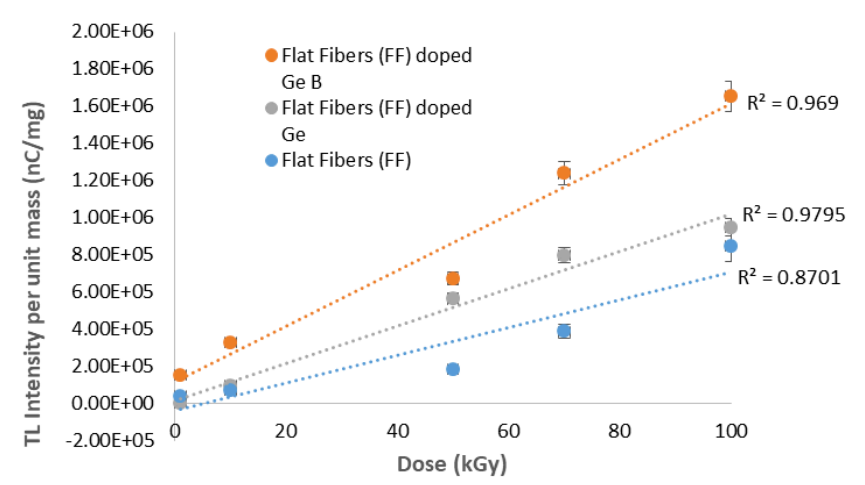

Figure 2 Linearity of Ge-doped, Ge-B doped and undoped flat fibers for kiloGray electron beam irradiation.

\section{Reproducibility}

For some TL materials, repeated usage might cause change to the deep, competing traps, and this change was accumulated with each reuse, causing the TL sensitivity to change over the usage period [13]. The study of reproducibility was performed by irradiating the Ge-B doped flat fibers to $5 \mathrm{kGy}$ on two different days and the results were shown in Figure 3. The results showed that the reproducibility of Ge- 
B doped flat fibers to be less than $5 \%$ variation based on standard deviation for 2 time sequential measurements.

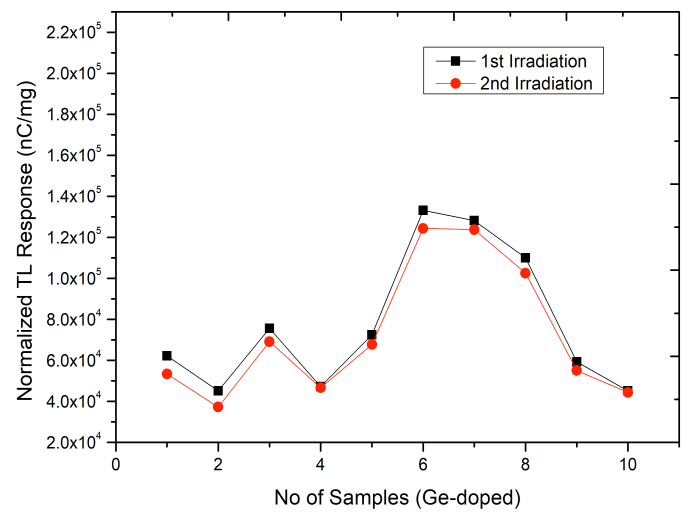

Figure 3 Reproducibility of Ge-B flat fibers after 2 irradiations.

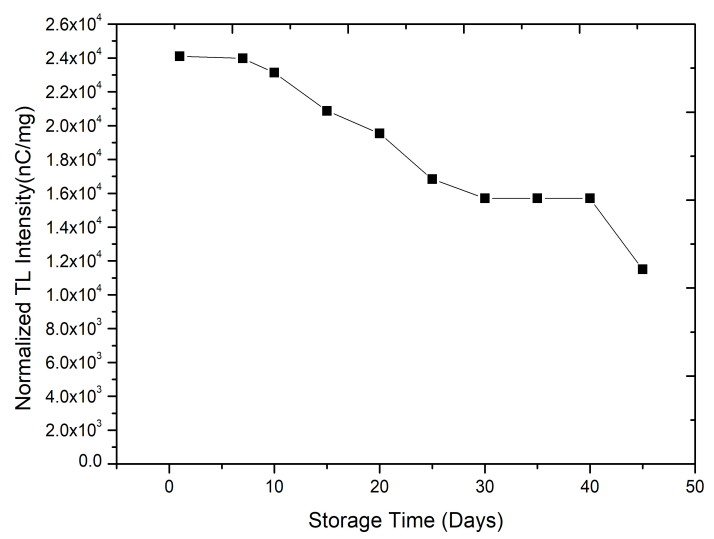

Figure 4 Fading for fabricated Ge-B doped flat fibers under normal ambient conditions.

Table 3 Fading for some commercial TLD materials [14].

\begin{tabular}{lll}
\hline TLD Dosimeter & TLD Materials & Thermal Fading \\
\hline TLD 100 & $\mathrm{LiF}: \mathrm{Mg}, \mathrm{Ti}$ & $5-10 \%$ per year \\
TLD 200 & $\mathrm{CaF}_{2}: \mathrm{Dy}$ & $16 \%$ in two weeks \\
TLD 400 & $\mathrm{CaF}_{2}: \mathrm{Mn}$ & $15 \%$ in three months \\
TLD 500 & $\mathrm{Al}_{2} \mathrm{O}_{3} \mathrm{C}$ & $3 \%$ per year \\
TLD 600 & ${ }^{6} \mathrm{LiF}: \mathrm{Mg}, \mathrm{Ti}$ & $5 \%$ per year \\
TLD 700 & $\mathrm{LiF}: \mathrm{Mg}, \mathrm{Ti}$ & $5 \%$ per year \\
TLD 800 & $\mathrm{Li}_{2} \mathrm{~B}_{4} \mathrm{O}_{2}: \mathrm{Mn}$ & $5 \%$ in three months \\
TLD 900 & $\mathrm{CaSO}_{4}: \mathrm{Dy}$ & $8 \%$ in six months \\
\hline
\end{tabular}

\section{Fading}

Fading is an important characteristic of TL dosimeters. Fading can be defined as the decrease in the TL signal due to ambient environmental conditions, including during transfer and storage. In order to determine the fading characteristics, the optic fibers were annealed and irradiated to a dose of $1 \mathrm{kGy}$ up to $4 \mathrm{kGy}$ of cobalt-60 (Gamma cell 220 Excel, Atomic Energy, Canada) at Universiti Kebangsaan Malaysia. The fibers were stored in a dark room at constant temperature of $27{ }^{\circ} \mathrm{C}$. This fading study for optical fibers samples demonstrated a small decrease of the TL response during the elapsed period of time. The obtained results in Figure 4 showed that after 2 months of storage period, fading was reduced by $8.7 \%$. Table 3 shows the fading rate for some commercial TLD materials. By referring to Table 3 , the fading characteristic of the optical fibers was similar to TLD-400.

\section{CONCLUSION}

The main dosimetric characteristics of new Ge-, B- doped flat fibers such as linearity of TL with dose, reproducibility and fading rate have been studied. The studied optical fiber demonstrated useful TL properties and it seemed to be an excellent candidate for use in TL dosimetry for food irradiation. Introducing the detection of irradiated food is very important for implementation of quality control at all levels. Therefore, the Ge-B doped flat fibers were seen to offer promising performance and matching the need for measuring food irradiation doses.

\section{ACKNOWLEDGEMENT}

The authors would like to thank Universiti Teknologi Malaysia for financial supported under the Research University Grant (4F501) and Ministry of Higher Education Malaysia for supporting this research financially through Fundamental Research Grant Scheme (FRGS). The electron beam facilities at Malaysian Nuclear Agency and Gammacell Lab, Universiti Kebangsaan Malaysia. This work was jointly supported by University of Malaya, Malaysia. This paper have been presented in KPFS 2017 at Lotus Desaru Beach Resort Johor Bahru Malaysia.

\section{REFERENCES}

[1] Farkas, J., Mohácsi-Farkas, C. (2011). History and future of food irradiation. Trends in Food Science \& Technology, 22(2), 121-126.

[2] Mclaughlin, W.L., Desrosiers, M. F., 1995. Dosimetry systems for radiation processing. Radiation Physics and Chemistry, 46(4-6 PART 2), 1163-1174.

[3] Chadwick, K. H., Oosterheert, W. F. 1986. Dosimetry concepts and Measurements Processing Food Irradiation, 37(I), pp.47-52.

[4] Whittaker, B., Watts, M. F. 2001. The influence of dose rate, ambient temperature and time on the radiation response of Harwell PMMA dosimeters. Radiation Physics and Chemistry, 60(1-2), 101-110.

[5] Huston, a L., Justus, BL. Falkenstein. 2002. Optically stimulated luminescent glass optical fibre dosemeter. Radiation protection dosimetry, $\quad 101(1-4), \quad$ pp.23-6. Available at: http://www.ncbi.nlm.nih.gov/pubmed/12382700

[6] Dambul, K. D., Mahdiraji, G. A., Amirkhan, F., Chow, D. M., Gan, G. K., Wong, W. R., Adikan, F. M. 2012. Fabrication and development of flat fibers. 2012 Photonics Global Conference (PGC). 13-16 December. Singapore: IEEE.

[7] Farkas J. 1988. Irradiation of Dry Food Ingredients. Boca Raton, Fla.: CRC Press.

[8] Kilcast D. 1995. Food irradiation: Current problems and future potential. International Biodeterioration and Biodegradation, 279-96.

[9] Morehouse K. M. 2002. Food irradiation-US regulatory considerations. Radiation Physics and Chemistry, 64, 281-284.

[10] Mahajna, S., Horowitz, Y. S. 1997. The unified interaction model applied to the gamma ray induced supralinearity and sensitization of peak 5 in LiF: Mg, Ti (TLD-100). Journal of Physics D: Applied Physics, 30(18), 2603-2619.

[11] Chen, R., McKeever, S. W. S. 1994. Characterization of nonlinearities in the dose dependence of thermoluminescence. Radiation Measurements, 23(4), 667-673.

[12] McKeever, S. W. S., Moscovitch, M. Townsend, P. D. 1995 Thermoluminescence Dosimetry Materials: Properties and Uses. England,: Nuclear Technology Publishing.

[13] Tugay, H., Yegingil, Z., Dogan., T., Nur, N., Yazici, N. 2009. The thermoluminescent properties of natural calcium fluoride for radiation dosimetry. Nuclear Instruments and Methods in Physics Research, Section B: Beam Interactions with Materials and Atoms, 267(23-24), pp.3640-3651.

[14] McKeever, S. W. S. 1998. Thermoluminescence of Solids. New York: Cambridge University Press. 